\title{
PROJETO UM SALTO PARA O FUTURO
}

\section{Pesquisa demonstra que, no Mato Grosso, projeto Um salto para o futuro carece de planejamento e recursos que levem em conta a realidade de ensino}

As discussões sobre a formação e a capacitação de professores estão presentes em todos os discursos oficiais sobre a melhoria da qualidade do ensino no país. Aliás, a formação de professores é vista como a responsável pela solução para os problemas educacionais.

Algumas atitudes em relação a essas discussões têm ocorrido ao longo dos anos e experiências nesse sentido têm sido implementadas. No Brasil e em outros países pobres, a educação a distância foi utilizada para se atingir algumas metas em relação à formação de professores, quer como formação inicial ou continuada.

Dentre essas experiências podemos citar o projeto SACI, para formação de professores leigos no Nordeste brasileiro, entre 1967 e 1974; o FUNTEV , no Mato Grosso do Sul, em 1985; o LOGOS, desenvolvido em todo o país a partir de 1973 , além de projetos desenvolvidos em nível internacional. Podemos citar alguns, como o UNRWA (United Nations Relief and Works Agency), em 1963, na Líbia, Síria, Jordânia e Faixa de Gaza; e o ANGOLA, em 1974, em Angola. Apesar dos investimentos efetuados nesses projetos, Geni de Lima nos informa que "de maneira geral não alcançaram seus objetivos"!

Além disso, Ivônio Barros Nunes identifica alguns erros que foram cometidos no desenvolvimento de projetos de ensino a distância: “(...) A falta de critérios de avaliação dos programas e projetos, a inexistência de uma memória sistematizada dos programas desenvolvidos e das avaliações realizadas, a inexistência de estruturas institucionalizadas para a gerência dos projetos, permanência de uma visão administrativa e política que desconhece os potenciais e as exigências do ensino a distância, fazendo com que essa área sempre seja administrada por pessoal sem a necessária qualificação técnica e profissional"2.

A identificação desse quadro foi o componente principal que nos incentivou a pes-

\section{O AUTOR}

Márcio Tadeu Magalhães

Professor do Departamento de Educação da Universidade Cândido Rondon e Assessor Pedagógico da Secretaria Estadual de Educação do Mato Grosso.

1. LIMA, Geni A. Identification des conditions de réussite d'un systeme de formation a distance des enseignantes leigos du Pantanal au Brésil. (Identificação das condições de sucesso de um sistema de formação a distância para professores leigos do Pantanal do Brasil). Quebec, Canadá: Universidade de Laval, 1990. 141p. (Dissertação de Mestrado).

2. NUNES, Ivônio B. A utilização da educaçâo a distância no Brasil - exemplos em curso. Revista Escola e Vídeo. Rio de Janeiro: Fundação Roberto Marinho, n. 11, 1994. p.30-32. 
quisar o desenvolvimento do projeto Um salto para o futuro em Mato Grosso. A partir do quadro que apresentamos, buscamos estudar as possibilidades desse projeto em relação ao seu objetivo principal que é o de oferecer formação continuada aos professores que atuam no ensino fundamental no país.

Em nossa pesquisa identificamos muitas dificuldades na utilização do projeto pelas escolas e pelos professores das mais diversas regiões do Estado. A partir do conhecimento das ações desenvolvidas durante a implantação e a implementação do projeto, concluímos que estas não foram suficientes. De maneira geral, muitos equívocos foram cometidos.

Buscamos também identificar as possibilidades que esse projeto oferece em relação às contribuições para os professores no processo de ensino e aprendizagem. Elegemos como parâmetros para identificar essas contribuições dois aspectos: o primeiro refere-se à mudança na prática do professor que participa do Projeto, na sala de aula com seus alunos. O segundo refere-se à análise dos índices de evasão e repetência escolar durante o período de 1990 a 1994.

Finalmente propusemos algumas alternativas que, em nosso entendimento, poderão possibilitar a utilização desse Projeto de forma a contribuir com os professores.

\section{O PROJETO E SEUS OBJETIVOS}

Um salto para o futuro é um programa da Secretaria Nacional de Educação Básica do Ministério da Educação em convênio com a Fundação Roquete Pinto e as Secretarias Estaduais de Educação. Surgiu a partir dos resultados da avaliação em uma experiência piloto desenvolvida por esses mesmos órgãos. Experimentado durante o período de agosto a dezembro de 1991, co- loca à disposição dos professores dos Estados de Alagoas, Bahia, Ceará, Espírito Santo, Minas Gerais e Rio Grande do Norte programas televisivos, visando ao aperfeiçoamento profissional.

A nova fase do projeto, denominada Utilização de satélite em Educação - Um salto para o futuro, propõe a manutenção do programa televisivo, apoiado por um jornal impresso e complementado pelo uso do fax e de canal de voz (telefone, que permite um diálogo entre os professores participantes da experiência e o centro de produção).

Um salto para o futuro, na abordagem pedagógica, centralizou seu trabalho em um diálogo com os professores em torno da constituição de conceitos básicos para a educação das crianças até a quarta série do primeiro grau, nas várias áreas do conhecimento. Em sua expansão, no primeiro semestre de 1992 , atendeu a 25 unidades da Federação.

O programa vai ao ar em canal aberto de segunda à sexta-feira, das $18 \mathrm{~h} 20 \mathrm{~min}$ às 19h, em dois blocos: o primeiro mostra um vídeo educativo, explorando em seu conteúdo aspectos metodológicos com ênfase no núcleo comum das quatro primeiras séries do primeiro grau. No segundo bloco, no Tira-dúvidas, especialistas respondem ao vivo questões levantadas pelos cursistas que estão nos telepostos, utilizando-se do fax e do telefone para contatar a central da Televisão Educativa (TVE). A transmissão é realizada através da TV Educativa - Canal 2, em cadeia com a TVE do Rio de Janeiro.

Os alunos assistem aos programas em locais aparelhados com monitores de televisão, videocassete, telefone e fax: são os telepostos. Existe, ainda, o apoio de um supervisor ou um orientador de aprendizagem em cada teleposto. Todos os programas são 
acompanhados por um boletim impresso que, além de tratar dos assuntos que foram veiculados pela televisão, contém sugestões de atividades pedagógicas.

O programa tem por objetivo propiciar meios de atualização ao professor de ensino de primeiro grau e aos alunos dos cursos profissionalizantes de formação de professores em nível de segundo grau, utilizando a educação a distância, através da conjugação de multimeios.

A proposta é que Um salto para o futuro se constitua em um diálogo aberto sobre as diversas abordagens teórico-metodológicas do currículo utilizado nas escolas brasileiras, centralizando o debate em torno da construção de conceitos básicos para a educação de crianças até a quarta série de ensino fundamental.

\section{ESTRUTURA E DIFUSÃO}

Transmitido em rede nacional via satélite, sua estrutura está composta de um bloco didático e um bloco de interação ao vivo (bloco Tira-dúvidas), no qual os alunos de todo o Brasil podem esclarecer dúvidas com a equipe de professores da TVE-Rio. A programação é elaborada na perspectiva da construção de conceitos, e as matérias são tratadas de forma interdisciplinar.

No desenvolvimento do programa diário são utilizados televisor, videocassete, telefone e material impresso. Um boletim diário com textos referentes às emissões televisivas é encaminhando às Secretarias Estaduais de Educação para a reprodução e distribuição aos envolvidos no programa. $\mathrm{O}$ pograma adota a recepção organizada. Ela é feita em telepostos, localizados em escolas ou órgãos de Educação.
Os alunos (chamados telealunos) são distribuídos em turmas (chamadas telessalas), onde uma dinâmica de grupo busca facilitar o processo interativo, e onde se desenvolvem as seguintes atividades:

a) leitura do boletim diário;

b) transmissão do programa do dia, constituído pela apresentação do tema através de vídeo (documentário ou depoimento), comentado em seguida pelo apresentador do programa ou por personalidade de conhecimento público;

c) intervalo no qual os telealunos elaboram perguntas a serem formuladas no bloco Tira-dúvidas;

d) realização do bloco Tira-dúvidas, através de contato direto entre a central de transmissão e os telepostos;

e) aprofundamento e aplicabilidade do tema ao cotidiano dos professores.

O programa é operacionalizado através de séries, com duração média de 90 dias. Cada série refere-se a um tema e é composta por determinado número de programas diários. É transmitido em horários e dias pré-estabelecidos, de forma sequiencial, a partir de uma grade de programação previamente encaminhada aos telepostos.

O Ministério da Educação, através da Secretaria de Educação Fundamental, por sua Coordenadoria de Educação a Distância, integrante do Departamento de Desenvolvimento Pedagógico, exerce uma função de articulador e gestor dos trabalhos. A Fundação Roquete Pinto, através da Diretoria de Tecnologia Educacional, é a produtora e emissora dos programas. O Ministério das Comunicações, através da Embratel, viabiliza a instalação da rede de telecomunicações. Um Comitê Consultivo, vinculado ao Ministério da Educação, é o responsável pe- 
la proposição das diretrizes técnico-pedagógicas. Interligam-se à Fundação Roquete Pinto as emissoras de rádio e televisão da Rede Brasil - Sistema de Radiodifusão Educativa, responsáveis pela transmissão local e pela co-participação na produção dos programas.

Os responsáveis pelo Projeto em nível nacional têm realizado avaliações após o término de cada série apresentada. De acordo com eles, essas avaliações indicam "o quanto o programa tem colaborado no aprimoramento profissional dos professores".

\section{UM SALTO PARA O FUTURO EM MATO GROSSO}

O programa foi implantado em Mato Grosso em 1992, no início da expansão nacional do Projeto. Nesse ano, o Projeto funcionou em 13 telepostos, distribuídos em escolas dos municípios de Cuiabá e Várzea Grande. Nesses telepostos estavam 350 telealunos.

Houve atraso de um mês na operacionalização do projeto no Estado em relação à transmissão nacional. Para suprir esse atraso na recepção das aulas pela TVE, a Secretaria Estadual de Educação providenciou a gravação dos 20 programas já veiculados. Em cada teleposto havia dois técnicos com as funções de supervisor e orientador de aprendizagem. Suas funções eram acompanhar, coordenar, planejar e avaliar as atividades pedagógicas.

Um problema de ordem estrutural, entre outros, marcou o início das atividades do projeto. Os espaços físicos destinados à organização das telessalas eram quase sempre inadequados (salas muito quentes e pequenas). Algumas telessalas funcionavam em salas de aula. A recepção dos programas ini- ciava-se às $18 \mathrm{~h} 20 \mathrm{~min}$. As aulas do curso noturno iniciam às $19 \mathrm{~h}$. Os telealunos eram obrigados a interromper as atividades. Alguns telepostos tinham também dificuldades com a sintonia do canal de emissão.

A Secretaria de Educação, justificando-se pela necessidade de concretizar sua proposta curricular, incentivou a expansão do Projeto no Estado, inclusive adquirindo antenas parabólicas para a instalação de telessalas. Assim, Mato Grosso iniciou a primeira série de 1993 com 93 telepostos. Estes estavam distribuídos em 26 municípios, abrangendo mais ou menos três mil professores. No entanto, a Secretaria de Educação registrou um aumento das dificuldades após a expansão das ações do Projeto.

O ano de 1994 marcou o início da desorganização do Projeto no Estado. As dificuldades aumentaram a partir do segundo semestre e a Secretaria deixou de dar apoio necessário ao desenvolvimento das atividades. Muitos telepostos foram desativados. Em 1995, o Projeto permaneceu desativado, apesar de alguns telepostos terem funcionado de forma isolada. Somente no final do ano de 1995 foram realizados seminários regionais com o objetivo de implementar suas ações.

\section{A tecnologia na escola}

Os recursos da tecnologia chegaram sistematicamente às escolas de Mato Grosso no ano de 1989, através do projeto Vídeo escola. No entanto, foi a partir do ano de 1992, com a implantação de Um salto para o futuro que ocorreu grande interesse dos dirigentes da Educação Pública Estadual pelos benefícios que poderiam chegar aos professores através desses recursos. 
Nos anos de 1992, 1993, até o início de 1994, a educação tecnológica (como foi chamada) ocupava lugar prioritário em todas as ações da Secretaria Estadual da Educação. Um elevado percentual dos recursos destinados à educação era utilizado para fazer avançar as metas da educação tecnológica. Nesse mesmo período foi criado o NET, Núcleo de Educação Tecnológica. Sua principal função era a de promover a articulação da Secretaria Estadual de Educação com os responsáveis, no Brasil e no exterior, pelas técnicas da educação tecnológica, além de coordenar os projetos.

Nesse mesmo período e a partir desse Núcleo, abriram-se muitas experiências nessa área. Firmaram-se convênios com instituições públicas e privadas - como a Universidade Federal de Mato Grosso e a emissora de televisão Brasil Oeste - visando ao desenvolvimento de projetos tecnológicos.

O primeiro ponto que destacamos, a partir de nossos resultados no estudo do desenvolvimento desse Projeto em Mato Grosso, é o caráter político-partidário que estava presente durante sua implantação.

Isto se expressou na indicação dos coordenadores dos projetos, na composição das equipes e até na indicação de técnicos para serem capacitados. Foram indicados profissionais que, muitas vezes, não tinham nenhuma vinculação com as atividades do Projeto, mesmo alguns que jamais tinham exercido qualquer função na Secretaria de Educação, principalmente os indicados para os cursos no exterior.

Quando concluíamos nossa pesquisa, no ano de 1995, não encontramos nenhum dos profissionais que foram capacitados através de ações do Projeto. Entre eles, mui- tos tinham se aposentado e outros, não pertenciam ao quadro da Secretaria de Educação, principalmente aqueles indicados para os cursos no exterior.

\section{PROBLEMAS E DEFICIÊNCIAS: ESCOLAS DOENTES}

$\mathrm{O}$ segundo ponto refere-se à infraestrutura das escolas. Não é difícil constatar a situação das escolas brasileiras e de Mato Grosso, em relação às suas deficiências estruturais. No caso particular deste Estado, as escolas encontram-se bastante atingidas pela insuficiência de recursos. As salas de aulas são quentes, a rede de esgotos não funciona, os banheiros não têm condições de uso, além de outros problemas.

É nesse quadro que chegam às escolas as ações do Projeto. De pronto surge o problema: como as escolas não possuem segurança suficiente para guardar o que está em seu interior, ficam os materiais (TV, videocassete e antena parabólica) acessíveis ao roubo. Aliás, encontramos casos de roubos desses aparelhos em 30\% das escolas. Em muitas delas, o Diretor, na tentativa de evitar o roubo, leva para casa ou tranca em sua sala (depois de reforçar a porta) esses materiais. A disponibilidade deles fica, de início, condicionada à transposição dessa dificuldade. Este é um problema que atinge também a operacionalização de outros projetos.

Os professores apontam, ainda, mais uma dificuldade: a sintonia do canal de emissão dos programas. Embora em sua proposta de expansão a Secretaria de Educação pensasse na aquisição de antenas parabólicas para todas as escolas, apenas $10 \%$ delas possuíam esse equipamento até 1995. 
Então, além da ausência de local disponível para o funcionamento das atividades do Projeto (elas acontecem até na secretaria da escola, nas salas de aula e os cursistas são obrigados a interromper as atividades quando se iniciam as aulas do período noturno), das dificuldades com a disponibilidade dos equipamentos, aparece o problema de sintonizar o canal da TVE, impossibilitando a recepção ou a gravação dos programas. Há casos em que os orientadores do Projeto realizam a gravação dos programas em suas casas, para posteriormente apresentá-las aos professores.

Algumas observações em relação ao gerenciamento do Projeto devem ser destacadas. Ele é gerenciado no Estado da seguinte forma: primeiro, pela equipe central, que está localizada na Secretaria de Educação; segundo, pelas equipes de coordenação, nos pólos. Elas são as responsáveis pelo desenvolvimento dos projetos. Suas atribuições abrangem todas as tarefas necessárias para que eles se realizem. Ao estudarmos o gerenciamento do Projeto ficou explícito o que já foi indicado anteriormente: o caráter político que, muitas vezes, interfere na organização das equipes e a ausência de infra-estrutura das escolas.

Identificamos ainda que, apesar do esforço dos membros dessas equipes, há outras dificuldades para a execução de suas tarefas, provocadas pela ausência de um planejamento sistemático para a implantação e expansão do Projeto no Estado. Essas equipes não contam com uma estrutura necessária para atender às rotinas dele decorrentes. Não há papel para as cópias, não há um sistema de envio de correspondência para os telepostos, não há nenhum convênio com os correios, o serviço de malote da SEDUC (Secretaria de Educação e Cultura do Mato Grosso) carece de verbas para manter seu fluxo e nem sempre está funcionando, não há recursos previstos para suas ações.

Os professores apresentaram outros problemas que classificamos como gerenciais em relação ao desenvolvimento do Projeto: a circulação dos boletins é um deles. Já sabemos que este Projeto se utiliza de material impresso como apoio às emissões da TV e que deve ser enviado aos professores cursistas. Ocorre que esses boletins enviados pelo produtor dos programas, através da Secretaria de Educação, não chegam aos telepostos em tempo de serem utilizados durante as emissões. Os professores assistem ao programa e só muito depois têm acesso ao complemento das aulas. A apresentação do conteúdo fica fragmentada, dificultando a compreensão.

Esses boletins, além de chegarem atrasados, vêm em número insuficiente para atender a todos os cursistas. E mais, a Secretaria de Educação e as escolas não têm condições de duplicar esse material. Implica a utilização de papel, cópias xerográficas e todo o aparato dessas máquinas copiadoras (fixador, cilindro etc.). Isto faz com que muitos cursistas não tenham acesso ao material complementar.

A entrega dos certificados aos cursistas aparece também como dificuldade gerencial em relação ao Projeto. Os responsáveis pelos entrepostos encaminham à Secretaria de Educação a relação dos cursistas de cada série. Ocorre, no entanto, que a Secretaria não possui em sua estrutura um órgão responsável pela emissão de certificados. Há uma dificuldade em identificar quem vai assiná-los. À equipe coordenadora do Projeto não é atribuída essa tarefa. A solução dessa questão fica condicionada a decisões de coordenadores ou outros ocupantes de cargos políticos na Secretaria. Isto provoca demora na emissão dos certificados e mesmo a perda de 
muitas listagens enviadas. Esses certificados são importantes na contagem dos pontos para a atribuição de aula, no início de cada ano. O não-recebimento dos certificados provoca desmotivação dos professores em participar das atividades referentes ao Projeto.

Em nossa conversa com professores identificamos outro problema que chamamos de gerencial. É a deficiência na sintonização do canal da $T V E$, dificultando o recebimento das emissões. Além disso, a falta de energia elétrica (verdadeira crise), em diversos municípios do Estado, faz com que muitas vezes não seja possível reunir os cursistas no horário previsto para as ações do Projeto.

A solução encontrada pelos professores coordenadores dos telepostos foi a gravação da programação, em outro horário (reprises só das emissões), para apresentação aos professores cursistas. As escolas não possuem recursos para a aquisição de fitas para a gravação dos programas. Isto é considerado pelos professores como mais uma dificuldade em seu desenvolvimento.

Em relação aos aspectos pedagógicos, os professores entrevistados apontaram como dificuldades, num âmbito mais geral, o fato de os professores não estarem capacitados a trabalhar usando os produtos de tecnologia. Mesmo em programas onde a metodologia do trabalho é esclarecida na programação (caso de Um salto para o futuro), os professores têm dificuldade de utilizar os conhecimentos adquiridos para a sua prática em sala de aula.

\section{FORMAÇÃO DEFICIENTE}

Em nossa pesquisa com os professores, $70 \%$ dos entrevistados apontaram a ne- cessidade de capacitação dos professores para o trabalho com os recursos da tecnologia. $\mathrm{Na}$ verdade, esse quadro expressa, de alguma forma, a necessidade de se promover um amplo programa de formação inicial de professores que atuam na rede pública de ensino. Um salto para o futuro, como formação continuada, atinge qualitativamente um número reduzido de professores.

Estamos em um mundo saturado de informações e o indivíduo precisa ter a capacidade de selecioná-las. Um mundo crescentemente automatizado, que dispensa o homem de certos esforços, requer dele, no entanto, um nível maior de competência para usar as novas tecnologias criticamente. Além do mundo do trabalho, o cotidiano da vida em sociedade exige que os trabalhadores e a população em geral adquiram uma capacidade cada vez maior de abstração, de domínio e de aplicação dos conhecimentos acumulados.

A educação desempenha importante papel na formação de consciências que aspirem a uma sociedade mais igualitária, solidária e democrática.

Na era da informação, não bastará para a educação municiar as escolas com equipamentos modernos. É necessário que se atente para a dimensão cultural das transformações sociais. É preciso aumentar as possibilidades de acesso e permanência na escola, elevando o nível de escolarização e profissionalização da população. E mais, decididamente não conseguiremos construir uma nova cidadania mantendo essas taxas de fracasso escolar. É preciso reverter as condições que concorrem para resultados tão negativos.

Assim, ao estudarmos Um salto para o futuro, buscamos identificar as contribuições do Projeto para o processo de ensino e aprendizagem, a partir do conhecimento dos índices de evasão e repetência escolar em 
Mato Grosso. Embora não se possa creditar apenas a esse Projeto a responsabilidade por esses índices, nossa curiosidade estava em verificar como se comportavam esses mesmos índices, a partir da implantação desse e de outros projetos com utilização dos produtos de tecnologia.

Para realizarmos esse estudo partimos dos dados referentes ao ano de 1990 até o ano de 1994. Nesse período esses índices, para o primeiro grau, variaram em média de $20 \%$ ao ano para a evasão, a partir da matrícula inicial, e outros $20 \%$ para a repetência escolar. O maior valor alcançado nesse período, tanto para evasão quanto para a repetência, foi no ano de 1994. Se considerarmos o fracasso escolar, os índices de permanência na mesma série de ensino provocados pela evasão e repetência, teremos então esses índices atingindo uma média de $40 \%$ !

A questão do fracasso escolar parece resultar da ausência de Política Educacional preocupada com o acesso à Escola para todos os cidadãos. E além disso, é preciso que haja uma preocupação maior dos governos, expressa em ações que diminuam as desigualdades sociais.

Então, se considerarmos os dados apresentados, não podemos afirmar que as ações do Projeto, no Estado de Mato Grosso, representem contribuição suficiente para a diminuição desses índices.

\section{FALAM OS PROFESSORES}

Nossa investigação buscou ainda identificar como os professores consideram as contribuições desse projeto para o processo de ensino e aprendizagem. Ao ouvirmos os professores em relação a essas possibilidades, estes se manifestam, a partir de seu en- volvimento com o Projeto, com as seguintes considerações:

1) Consideram que este projeto pode contribuir para a melhoria da qualidade do ensino. Para um percentual expressivo desses professores, a melhoria da qualidade do ensino está em "oferecer condições para que o aluno aprenda e tenha mais oportunidades no mercado de trabalho e na vida". Os professores pesquisados acreditam que este Projeto pode ajudar nesse sentido, sobretudo proporcionando aos professores, envolvidos nas suas ações, condições de apoiar seus alunos nessa direção.

2) Apontam a inovação das técnicas de ensino como outra contribuição do Projeto. $E$ isso aparece de duas formas: traz a sensação aos professores de estarem fazendo parte dos avanços da sociedade moderna; estas inovações técnicas trazem a possibilidade, a um certo número de professores, de introduzi-las em seu trabalho de aula, alcançando resultados satisfatórios.

Entre os professores participantes da pesquisa um número considerável valoriza a possibilidade de receberem essas informações através desse Projeto. Muitos professores, nas mais distantes regiões do Estado, antes do Projeto, passavam muito tempo sem conhecer as novas discussões no campo educacional. Apesar de pouco utilizar-se dos conhecimentos e das novas técnicas, apresentadas nesses programas para sua prática em sala de aula, essas informações possibilitam ao professor o enriquecimento das discussões nas diversas atividades desenvolvidas na escola.

Se levarmos em conta o que foi identificado até agora em relação ao desenvolvimento das ações do projeto $\mathbf{U m}$ salto para o futuro em Mato Grosso, talvez possamos afirmar que elas estão bastante prejudicadas. Pelo menos no modelo que é proposto pelo MEC/Fundação Roquete Pinto, não se 
realiza nesse Estado. Pudemos verificar que essas ações acontecem de forma isolada (em algumas das 580 escolas estaduais) e de forma diferenciada do que é a proposta original. Acontecem como resultado de adaptações feitas de acordo com a realidade da escola que as desenvolve, o que não deixa de ser válido.

Tornou-se complicado identificar, no momento de nossa pesquisa, significativas contribuições do Projeto para a prática do professor. E ainda mais, não há uma comunicação sistêmica entre as equipes, nem mesmo com os condutores dos programas,

Resumo: O Projeto de Educação a Distância Um salto para o futuro, voltado para o aperfeiçoamento de professores de primeiro e segundo graus, é analisado a partir de pesquisa do autor, que faz um balanço sobre os problemas de sua implantação e desdobramentos no Estado do Mato Grosso.

Palavras-chave: Um salto para o futuro, educação a distância, educação tecnológica, Mato Grosso dificultando o encaminhamento de soluções para os diversos problemas.

De maneira geral, podemos dizer que a implantação de Um salto para o futuro em Mato Grosso repete o que tem se praticado no decorrer dos anos em relação aos projetos desenvolvidos com o objetivo de formar professores.

É necessário dizer ainda, ao concluir esta etapa de trabalho, que o envolvimento atual com este e outros projetos na Secretaria Estadual de Educação tem possibilitado mudança nas atitudes com respeito às suas ações.

Abstract. The externally conducted Educational Project Um salto para o Futuro (A Stride towards the Future) conceived for the professional development of elementary, secondary and high school teachers is analyzed based upon a research carried out by the author in which he assesses the problems involved in its implementation and also the developments of the project in the State of Mato Grosso.

Key-words: Um salto para o Futuro (A Stride towards the Future), externally promoted education, Mato Grosso, technological education. 